\title{
BMJ Open How do people who use drugs experience treatment? A qualitative analysis of views about opioid substitution treatment in primary care (iCARE study)
}

\author{
Paula Cristina Gomes Alves (1) , ${ }^{1,2}$ Fiona A Stevenson, ${ }^{2}$ Sophie Mylan, ${ }^{2}$ \\ Nuno Pires, ${ }^{3,4}$ Adam Winstock, ${ }^{5}$ Chris Ford ${ }^{6}$
}

To cite: Alves PCG,

Stevenson FA, Mylan S, et al. How do people who use drugs experience treatment? A qualitative analysis of views about opioid substitution treatment in primary care (iCARE study). BMJ Open 2021;11:e042865. doi:10.1136/ bmjopen-2020-042865

- Prepublication history and additional material for this paper are available online. To view these files, please visit the journal online (http://dx.doi. org/10.1136/bmjopen-2020042865).

Received 20 July 2020 Revised 16 December 2020 Accepted 17 December 2020

Check for updates

(C) Author(s) (or their employer(s)) 2021. Re-use permitted under CC BY-NC. No commercial re-use. See rights and permissions. Published by BMJ.

For numbered affiliations see end of article.

Correspondence to Dr Paula Cristina Gomes Alves; p.c.gomesalves@gre.ac.uk

\section{ABSTRACT}

Objective To understand the most significant aspects of care experienced by people in opioid substitution treatment (OST) in primary care settings.

Design Semistructured individual interviews were conducted, following the critical incidents technique. Interview transcripts were analysed following a thematic analysis approach.

Participants Adults aged 18 years or older, receiving OST in UK-based primary care services.

Results Twenty-four people in OST were interviewed between January and March 2019. Participants reported several aspects which were significant for their treatment, when engaging with the primary care service. These were grouped into 10 major themes: (1) humanised care; (2) individual bond/connection with the professional; (3) professionals' experience and knowledge; (4) having holistic care; (5) familiarity; (6) professionals' commitment and availability to help; (7) anonymity; (8) location; (9) collaborative teamwork; and (10) flexibility and changes around the treatment plan.

Conclusions This study included first-hand accounts of people who use drugs about what supports them in their recovery journey. The key lessons learnt from our findings indicate that people who use drugs value receiving treatment in humanised and destigmatised environments. We also learnt that a good relationship with primary care professionals supports their recovery journey, and that treatment plans should be flexible, tailor-made and collaboratively designed with patients.

\section{INTRODUCTION}

The prevalence of illicit drug use in the UK has remained stable over the last decade, with 1 in 10 adults aged $16-59$ years self-reporting using illicit drugs in the last year. ${ }^{1}$ However, drug mortality rates have been escalating, with the number of opioid-related deaths per year rising from 579 in 2012 to 1336 in 2018, the highest number and the highest annual increase $(16 \%)$ since $1993{ }^{2}$

In the UK, treatment for drug use can be provided free of cost via the National Health Service (NHS). They recommend that general
Strengths and limitations of this study

- Good breadth of experiences coming from a diverse sample (different genders, various treatment lengths, four services across three UK cities).

- Balanced overview of aspects that make treatment helpful and hindering for people who use drugs.

- Limited representativeness to other people and settings due to the study's small sample size.

- Participants identified and selected by general practitioners, which may have biased the recruitment process.

- Our study design hindered the identification of people with limited treatment adherence, and whose experiences could have been informative.

practitioners (GPs) are 'a good place to start' as they can 'offer treatment at the practice' or refer to a 'local drug service' for specialist treatment. ${ }^{3}$ Despite free and effective treatment available, access to drug addiction treatment is suboptimal in the UK. ${ }^{4}$ Moreover, reports have shown that only $48 \%$ of people successfully complete their treatment plans, and that the lowest rate of successful treatment completion $(25 \%)$ was found in people who use opioids. ${ }^{4}$

While many factors contribute to poor treatment outcomes, including comorbidity and inadequate dosing of opioid substitution treatment (OST) medication, it is likely that treatment delivery issues also play an important role. For example, in one study of OST in Australia, although overall satisfaction with OST was quite high $(3.8 / 5)$, issues related to clinic atmosphere, frequency of clinic attendance, dispensing hours and lack of takeaway doses were commonly cited as areas of concern for people. ${ }^{5}$ In other studies, issues located within the clinical population itself such as low motivation and conflicts with staff were among the most common 
reasons for dropout. ${ }^{6}$ A particularly pertinent finding relates to the reported power imbalances between people who use drugs and professionals, where stigma, stereotypes and discriminatory practices are embedded within the cultural context of a drug service. ${ }^{7}$

In the UK, in $2017-2018,14.4 \%^{8}$ of those receiving OST obtained their prescription from GPs. In primary care, people in OST can also engage with other allied health professionals, such as key workers. Key workers are trained health and social care professionals who deliver psychosocial interventions and support people who use drugs making positive changes and work towards recovery. They also liaise with GPs to manage prescriptions, as well as collaborating in assessments and clinical reviews.

As specialist drug and alcohol treatment services have seen a decline in funding and move towards third sector provision, ${ }^{9}$ the role of primary care in the delivery of OST has never been more important. Primary care is the second most common provider of OST in the UK, either as the sole provider or in a shared care process with specialist services. Primary care provides an opportunity for people who use drugs to be treated like any other person and enables health conditions, including mental health needs, to be addressed alongside treatment for drug use. ${ }^{10}$ Primary care facilitates the identification of issues related to drug use in people seeking help for other physical and mental health issues ${ }^{11}$ and can 'normalise' drug treatment, with the potential to reduce the stigma of attending a specialist drug service. ${ }^{7}$

There are, however, challenges to managing drug use in primary care. Press $e t a l^{12}$ interviewed people in OST in primary care in Baltimore (USA). They found that optimising the interpersonal relationship between people who use drugs and physicians is key in OST. Short appointments in primary care may not allow enough time for more complex cases or developing supportive rapport with people. ${ }^{12}$ There is also literature suggesting that people who use drugs 'wished' their GPs had greater knowledge about drugs and addiction, which in turn would enable them to foster less judgemental relationships and treat people who use drugs as "people they care about'. ${ }^{12}$

The experiences of people in OST via UK-based primary care services have been little explored. Given that primary care is an important setting for the care of people who use drugs, it seems imperative to understand what we can learn from them in terms of how it feels to receive treatment in this setting. In doing so, there is scope to improve treatment experiences and optimise successful outcomes, as well as promoting the agency of those for whom the services are designed. Also, knowing what aspects of OST are valuable to people allows us to better adjust for any changes/restrictions affecting treatment delivery (eg, financial crisis).

This study aimed to understand the experience of people in OST in primary care settings. More specifically, it sought to identify the aspects of care which were perceived by people who use drugs as most significant to their recovery journey, in their own words, including aspects which were either helpful or that made it difficult to be in treatment.

\section{METHODS}

\section{Study design and setting}

This was an exploratory qualitative study based on individual, semistructured interviews with people who use drugs. These were recruited from primary care services in three UK urban areas (Leeds, London and Nottingham) and one charity (third sector provider) providing OST on a shared care basis (London).

\section{Patient and public involvement}

One person from the target population was invited to comment on the research proposal, the application form for the Ethics Committee and the interview schedules to ensure that the methodology and terms used were nonjudgemental, meaningful and feasible in this context. During data analysis, another person in OST was invited to comment on the preliminary version of the thematic map to ensure our interpretations were aligned with the experience of this group in treatment.

\section{Participants}

Study participants were adults (over 18 years old) receiving OST in primary care, either with methadone or buprenorphine. Potential participants receiving other forms of treatment for licit substances (eg, alcohol and tobacco) or receiving OST via specialist services only were not included in the study.

\section{Recruitment}

To identify eligible participants, we worked with GPs and key workers delivering OST in primary care, invited through UK professional networks (eg, https://smmgp. org.uk/). These professionals explained the study to people in OST at their practices. Those who met the inclusion criteria, expressed an interest and agreed for their contact details to be shared with the research team were invited to the study. Whenever possible, study participants were purposively selected according to age, gender and length of time in treatment (ie, less than 6 months, 6-12 months, $1-5$ years, $>5$ years) to obtain a variety of experiences. Interviews were conducted between January and March 2019. All study participants were asked to read the information sheet and to provide written consent before the interview.

\section{Data collection}

Interviews were conducted by the first author (PCGA, PhD in Psychology, researcher in clinical psychology for 10 years), who was unknown to participants prior to the interview. The interview topic guide (online supplemental appendix 1) was semistructured and based on the critical incidents technique. ${ }^{13}{ }^{14}$ During the interview, study participants were encouraged to discuss their personal experience, in their own words, and to focus on issues raised by them, with limited 
prompts from the researcher. Interviews were audio-recorded with study participants' permission and transcribed verbatim by a professional transcription service. Before the interview, study participants were encouraged not to mention any names of professionals, services, locations or any other information that could identify them. Any potentially identifiable information shared was removed from transcripts. At the end of the interview, study participants were asked to complete a basic sociodemographic form (eg, age group, employment status, educational background). All study participants were given a $£ 20$ voucher as recognition for their support. Interviews were conducted in a private room within the primary care service or charity, in which only the researcher and study participant were present to ensure confidentiality.

\section{Data analysis}

A thematic analysis approach ${ }^{15}$ was adopted using a 'bottom-up' iterative process. Thematic analysis was chosen because it is a flexible, non-theoretical approach that aims to examine 'the perspectives of different research participants, highlighting similarities and differences, and generating unanticipated insights' ${ }^{16}$ Analysis was primarily conducted by the first author (PCGA) in collaboration with a multidisciplinary research team (FAS, medical sociologist; SM, GP registrar; NP, clinical psychologist; AW, consultant addiction psychiatrist; CF, GP with special interest in substance use).

The codes were first generated deductively, by interpreting data according to what was described as 'helpful' and 'not helpful' for people in OST; and then inductively, according to the underlying meaning of each text unit. Regular meetings were held between the first author and other team members to reduce the risk of bias in the analysis. The preliminary version of the thematic map was discussed with a study participant to seek feedback on whether the themes and subthemes reflected the experience of people in OST in primary care.

The first author recorded her thoughts in a researcher diary during data analysis to increase critical reflexivity and keep a $\log$ of all the decisions made around the coding and theme generation process (a summary of key steps is presented in online supplemental file 1). Data were analysed with the support of NVivo V.12.

\section{RESULTS}

\section{Participant characteristics}

Twenty-four people in OST were interviewed until data saturation was reached. The majority $(n=20)$ were prescribed methadone. Most interviews $(n=16)$ took place at the study participant's general practice. Eight interviews were carried out at a charity. Interviews lasted an average of $28(\mathrm{SD}=8.6) \mathrm{min}$, ranging from 14 to 44 . See table 1 for a summary of sample characteristics.

\section{What is the experience of people receiving OST in primary care?}

Ten major themes emerged from the 24 interviews with people in OST about their treatment experience. These themes represented aspects deemed as important for people who use drugs when engaging with GPs and key workers in one-to-one consultations; and when engaging with the primary care service in general, for example, experience of booking appointments, interactions within administrative staff or service accessibility issues. These themes are summarised in table 2 and are described in more detail.

Theme 1: 'Being treated like a human being' (humanised care) During the interviews, study participants highlighted that 'being treated like a human being' by GPs and key workers was crucial to their recovery journey, which was referred 219 times across the study. This meant having the opportunity to discuss clinical decisions, instead of being forced to engage in a treatment plan unilaterally designed by GPs and/or key workers; being respected as a person and having treatment tailored to individual needs, as opposed to being provided with standardised information and 'one-size-fits-all' plans. As Rob described during his interview, being treated as a human being while on methadone treatment means feeling 'normal' as opposed to an 'addict'. Similarly, Josh described how helpful it feels coming to the service and "being treated like a person, I know I can come here... and staff are not going to get 'sit over these', or 'get him out quick'. They hear what you are saying. I think that's important". For another study participant taking buprenorphine, William, being valued as a person implied that professionals "don't push you in a direction and say, 'This is what you should do.' They look at what you need and what direction you want, and how you want to do it".

\section{Theme 2: 'I know she is on my side' (individual bond/ connection with the professional)}

The individual bond/connection with GPs and key workers was reported as one of the most important aspects of treatment, which emerged 159 times during interviews. A good connection encompassed feeling

Table 1 Study participants' self-defined characteristics $(\mathrm{N}=24)$

\begin{tabular}{ll}
\hline & $\mathbf{N}$ \\
\hline Gender & Women: 10; men: 14 \\
Ethnicity & White British: 19; other white background: 3; Asian Indian: 1; Black Caribbean: 1 \\
Employment status & Full-time: 2 ; part-time: 1; unemployment: 21 \\
Education & No qualification: 10; GCSEs/A-levels: 10; higher education diploma: 3; postgraduate education: 1 \\
\hline
\end{tabular}


Table 2 Thematic map representing the experience of people in OST in primary care

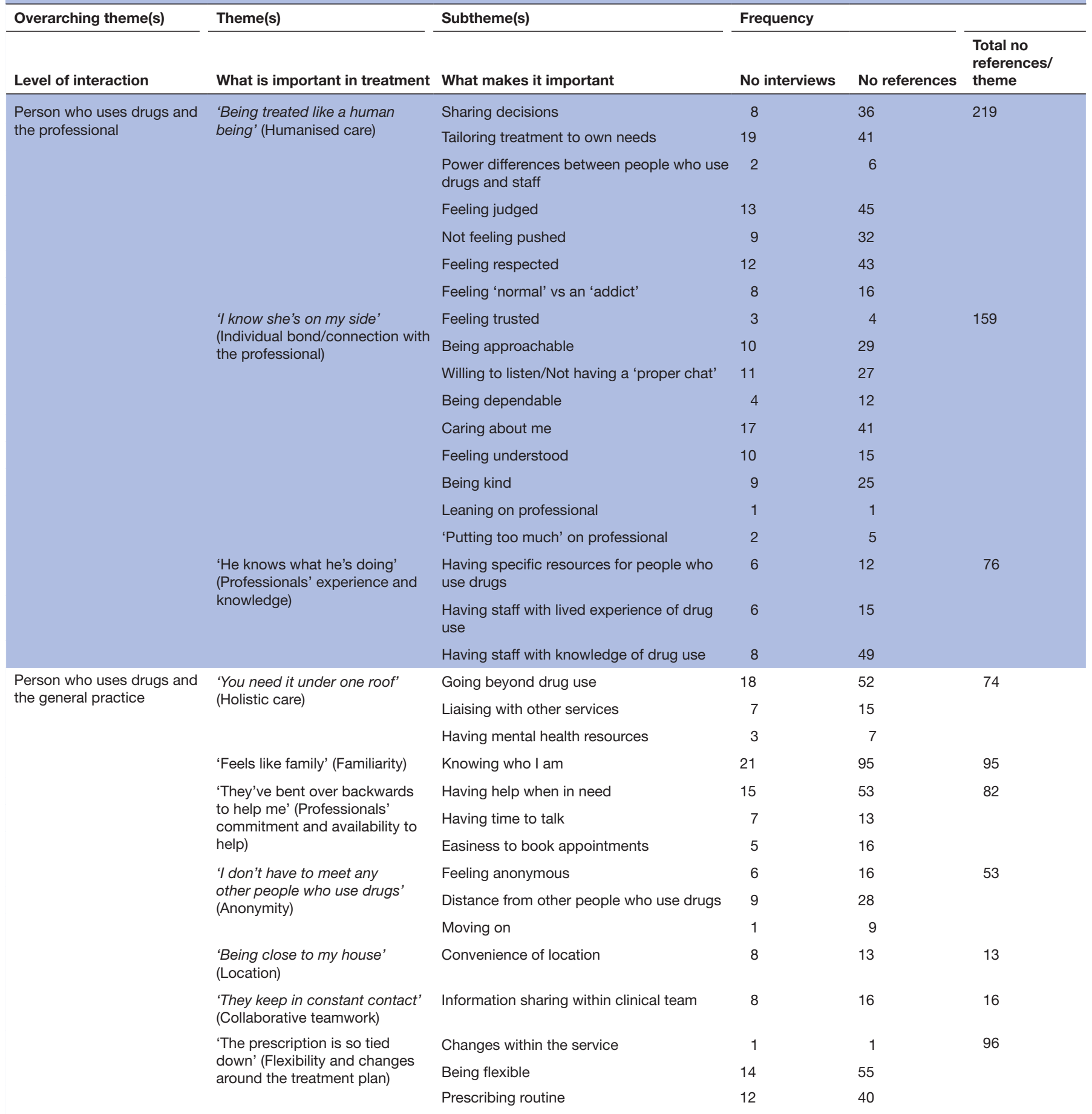

OST, opioid substitution treatment.

trusted, understood and professionals being approachable, caring, dependable, kind and willing to listen. Jane, for instance, was started on a prescription of methadone less than 6 months ago, and she values that her GP is "very understanding. I've had a few times when it's been a bit wobbly. I've had a few stressful situations and I've had a couple of lapses as well, but I feel like I can be open. I don't need to hide anything. He treats me like, 'That's fine'." In line with this, not feeling cared for by professionals was also hinted as a potentially negative experience. Mark, for instance, explained that some key workers are "doing it because they need a job, because they're in a situation where they can't get anything else. So, they do it, but how much do they actually care about you? Do they really give a shit? That's the truth. I think some people do; I think some people don't." Ricky raised a similar point in his interview, by saying how important it was that "they do care, I know that they're not just there because they have to be there, they're not just doing it because they're 
getting paid, if you get what I mean. He genuinely helps me out."

\section{Theme 3: 'He knows what he's doing' (professionals' experience and knowledge)}

Study participants valued when GPs and key workers in primary care had knowledge of drug use and awareness of resources for people who use drugs, which emerged 76 times in this study. For instance, Claire, who has been prescribed methadone for the past 2 months, said that the GP "made [her] feel reassured because he was obviously very capable. He'd obviously been doing this for years". Michael expressed similar views to Claire's in his interview: "Some have been so long, or they've been working for addiction for so long, or whatever, and they know everything. They know the behaviour, they know the lies that they say when they're trying, sometimes, manipulating, to get what they want. You know, they know all these things." Some study participants also valued staff with lived experience of drug use. One such person was Joe, who had been on buprenorphine for 7 years in the same service. Joe highlighted that if "they've never been on drugs so, they'll never understand. (...). If they knew that, the pain that I've gone through this week", they would prescribe "something to help me sleep at night".

\section{Theme 4: 'You need it under one roof' (holistic care)}

Another aspect highlighted by study participants as significant to their recovery journey was having further mental and physical healthcare, which emerged 74 during the interviews. This was described as going beyond drug use in their treatment plans, and the opportunity to liaise with other health and social care services and charities. For Mary, who is prescribed buprenorphine, this is important because drug use "causes a lot of medical problems. So, you always have backfires in one or the other, so it makes it really helpful that you can come to deal with both issues at the same time. So that you can come and get both sorted." An emphasis was put on mental health resources, which study participants such as Laura believed to be key for recovery: "I think if they're doing shared care, they should allow shared care to have a little bit of mental health or something like that here as well, maybe. So, it's not all on my doctor". Finally, some participants also valued having support beyond health issues. As James put it: "I got help with housing. I've had help with my benefit claim and my methadone, general health. Quite a spectrum really. I mean, I had a benefit claim not long back and I had to get my doctor write me a letter for all them, and that doesn't seem to be any trouble. And he doesn't charge you for those. Usually a doctor will charge you a tenner for them, but they don't here".

\section{Theme 5: 'Feels like family' (familiarity)}

Study participants valued the experience of feeling like family' at the primary care service, which was discussed 95 times during the interviews. In our study, this meant having GPs, recovery workers and administrative staff who have known study participants for long periods of time, and who are familiar with their personal life circumstances and how they have changed over time. As an example, Neil reported that prior to being prescribed with buprenorphine, his GP had "known me as a person since I was like 20 years old, but I've always been having problems with drugs, so she's always known me as that kind of person". Robert shared a similar experience, when he said that "they all got that same kind of environment, that same kind of attitude. It's like one big family here and when you come you all get treated like that. So, it's very welcoming." Consequently, the opposite situation-lack of familiarity-was reported as a negative experience. For instance, in his interview, Ricky shared how he disliked not being recognised by his GP: "I've seen the woman like five times and when I went last month she said, 'Have I seen you before?' Like she doesn't even know me."

\section{Theme 6: 'They've bent over backwards to help me'} (professionals' commitment and availability to help)

Study participants valued when they felt that GPs, key workers and administrative staff went over and beyond their expected roles or duties to support them, including being available whenever needed. This theme was discussed 177 times during the interviews. For instance, this meant being told by professionals to contact the service at any time, either in person or via telephone, or facilitating the process of booking appointments. This was particularly meaningful for people starting their treatment, such as Michelle, who valued when "the doctor said to me that if I just turned up here and I didn't have an appointment he'd always see me. That's quite nice to know that I've got that support." In line with theme 5, the level of commitment from professionals was also highlighted when support was needed beyond drug use issues, as Claire put it: "I've always found that they've always tried to go above and beyond what I expected would be possible. They've turned around and said, something like when I say, even before I knew that a problem was going on with the paralysis, I was just stuck in a bed and I couldn't go to the toilet and I was having trouble and they came out and the doctor was able to bring me some NHS provided nappies." Having time to talk in consultations was also highlighted by study participants as a key aspect in their recovery journey. As a person receiving buprenorphine for more than 5 years, Martin explained that if "you're still in the situation where you're seeing your keyworker and they've got someone else coming in 20 minutes' time. You can't really go into too much. 'Why are you stressed? Why can't you sleep?' It's not as simple as that."

\section{Theme 7: 'I don't have to meet any other people who use drugs' (anonymity)}

Receiving treatment in primary care alongside the general population was another aspect valued by people in OST, which was mentioned 53 times during interviews. In other words, people in OST appreciated feeling anonymous, which meant attending for generalised health concerns, and where other people were not aware of their drug use issues. From this point of view, study participants considered that going to primary care for their OST made them feel like moving on to a different stage in their recovery 
journey. For instance, John has been prescribed OST for over 5 years and the anonymity of being at a GP surgery made him feel "confidence, nobody knows about you, why you are in there. Just surgery practice and everybody's doing their business and that's it. It's fine." A similar experience was reported by Connor, who has been receiving buprenorphine for over 1 year in primary care. In Connor's words, "I'm a druggie, don't get me wrong, but I'm a recovering druggie, and I don't like to be reminded of that. I don't like to sit with people that are just squiffy, that are- You can see they're on drugs, and they're sat there rubbing their noses and blooming drinking." Mark's experience at primary care was similar: "(at the GP), I'm not sat with a load of other-This sounds really contradictory and condescending for myself, but I'm not sat with all the druggies that are still active."

\section{Theme 8: 'Being close to home' (location)}

Being engaged with a service that is geographically close to home was mentioned 13 times as an aspect that impacts the recovery journey during OST, due to its ease and convenience. For instance, Gary has been receiving treatment with methadone for over 5 years at his local GP surgery, and according to him, he likes 'this place because I've been living just around here, it's not that far from me you see'.

\section{Theme 9: 'They keep in contact all the time' (collaborative teamwork)}

Study participants valued when different GPs, key workers and other health professionals worked collaboratively in their treatment plan, which emerged 16 times during the interviews. This referred to when professionals shared information about their clinical situation. Rebecca has been taking methadone for 10 years and finds that it "works well, yes. I think it's quite important, because at the end of the day, I suppose, they are only workers. So, they can fall back on the doctor just as I can. So, yes, I actually do think it's a good thing". From this perspective, study participants believed that lack of communication between professionals can lead to negative outcomes. Michael, who has been receiving buprenorphine for 3 years, for instance, discussed how 'horrendous' it was when his prescription was "stopped because they changed my worker and that worker didn't know my situation and they stopped my script." Maria shared a similar experience and how that affected her consultation schedule: "If they shared the information, which obviously should be in a file, they'd know I was never going to be there for six o'clock because I've been working for years. My shift hasn't changed in that sense."

\section{Theme 10: 'The prescription is so tied down' (flexibility and} changes around the treatment plan)

Finally, the flexibility of the service and the treatment plan was also highlighted by study participants as important to recovery, which was mentioned 96 times during the interviews. This referred to situations in which the clinical and administrative staff adjusted for any changes in the treatment plan, as well as the impact of changes within the service in general. For instance, Julie has been on buprenorphine for 3 years and feels that it is very helpful when there is flexibility around the prescriptions, so that "if you have messed up or you have made a mistake, you can still ring them the next day or come in the next day and they will try and find somebody to see you and give you a help." Another study participant on buprenorphine, Paul, shared how changes within service staff impacted him during treatment: "I could have relapsed [because of the error in the prescription]. I could have ended up back on drugs after years and years - buying my house, buying a nice car, working my way up at where I'm at and getting myself back on track. From someone that didn't know what they were doing, just coming in and pulling a script, thinking they were clever, that could have put me back to scratch, back to day one". Participants also expressed frustration about the impact of missing appointments on their care plans. As Robert put it: "That side is more of a frustration, because they'll send me letters saying, 'You didn't turn up to this appointment, you were ten minutes late to this one, we're going to stop your script if you don't...' I've been working for years".

\section{DISCUSSION}

This study sought to understand the experiences of people receiving OST via GPs and key workers in primary care services. In the next sections, we will discuss the key lessons learnt from study participants and reflect on how these lessons can help us improve the quality of care provided to this population, from a primary care perspective.

People in OST want to be treated like any other person and value continuous, compassionate and holistic care, which can be provided by primary care professionals

In the UK, drug use treatment has been successfully delivered in primary care settings for over 30 years, as part of an effort to normalise treatment delivery and bring it in line with other chronic conditions. ${ }^{17}$ This is illustrated by the growing number of people engaged in OST in primary care, and the increasing training opportunities and guidelines for primary care professionals managing substance use (eg, RCGP Certificate in the Management of Drug Misuse Parts 1 and 2). ${ }^{17}$ In our study, it was encouraging to learn that people perspectives are aligned with that of professionals and researchers, that is, that primary care provides a valuable setting to deliver treatment to people with problems related to drug use.

Primary care services are designed to accommodate a whole variety of concerns from 'cradle to grave and everything in between'. ${ }^{17}$ On the other hand, drug use is associated with various health conditions across the lifespan, from adolescence to older adulthood. ${ }^{18}$ Hence, primary care can play an important role in caring for the person and their comorbidities and not only his/her drug use issues. This role seems to be acknowledged by our study participants, with the experience of having care at primary care deemed as important for their recovery journey. 
Privacy concerns and how primary care supports people in keeping their anonymity as people who use drugs was another aspect appreciated by study participants. This has been addressed in the literature, in which people refer to being in methadone treatment as a 'dirty secret' that needs to be protected, so they can 'pass as normal' ( $p$. 263). ${ }^{19}$ Previous studies have also suggested that people fear having drug use in their clinical records and how that may negatively impair their general healthcare. ${ }^{20}$ While clinic record confidentiality is a basic right for all those receiving healthcare in the UK's National Health Service, these comments highlight the stigma many people feel. In other words, whenever possible, non-specialist treatment may be preferable due to its role in mitigating stigma.

Another aspect which people who use drugs seem to value when in treatment is continuity of care. Research indicates that long-term trusting relationships between people and GPs decrease overall mortality, cardiovascular events and healthcare costs. ${ }^{21}$ Continuity of care has also been associated with better treatment outcomes and quality of life in chronic conditions. ${ }^{22}$ For instance, in other chronic conditions such as diabetes, people report that primary care professionals are vital in coordinating and facilitating access to specialist care when needed. ${ }^{23}$ This means that when drug use treatment is addressed in primary care, people not only experience continuity of care; but are also more likely to better engage with specialist services, for example, inpatient units for detoxification, bringing down barriers such as fear of treatment or admission difficulties. ${ }^{24}$ This is crucial when caring for comorbid conditions among an ageing population, allowing GPs to see people, instead of single conditions in isolation, which is particularly important for those with mental health/pain issues. ${ }^{25}$

Considering this, our paper not only reinforces that managing drug use fits within the generalist approach of primary care services; but also, that people who use drugs value the opportunity of having primary care professionals involved in their recovery journey. Therefore, these findings point towards a continued involvement of primary care in the delivery of drug use treatment, and that this is accounted for in local, regional and national healthcare budgets.

\section{Further training about drug use and OST could be provided to primary care professionals}

Study participants found it helpful when they perceived professionals as experienced and with expert knowledge about drug use. Even though primary care is the second most common provider of OST in the UK, ${ }^{8}$ research shows that professionals in general practices may be reluctant, less prepared and motivated to manage drug use in comparison with other health conditions. ${ }^{26}{ }^{27}$ It has also been suggested that primary care professionals may find it difficult to enquire about drug use in their consultations, and that they may experience a lack in confidence, knowledge and skills when dealing with stigma around drug use and managing the complex needs of people who use drugs. ${ }^{20}$ Despite the existing career and professional development opportunities in the management of drug use in primary care, it would be advantageous to strengthen the curricula of health professionals, medical students and GPs in how to engage with this group. This is particularly relevant for professionals working in geographical areas where drug use is prevalent, and where people who use drugs are likely to seek medical care for various physical and mental health concerns. Increasing training to GPs is also paramount in a current scenario where prescription rates of long-acting and short-acting opioids for pain management are escalating in the UK. ${ }^{28}$

In addition to having expert knowledge, people who use drugs valued key workers with lived experience of drug use. There is limited evidence on the effectiveness of interventions delivered by staff with lived experienced. However, findings drawing from peer-led interventions are promising, as they indicate that involving staff with lived experience is potentially associated with a reduction in the use of tobacco, alcohol and cannabis. ${ }^{29}$ The involvement of peers in treatment as a positive experience is not surprising. Professionals with lived experience of drug use not only share an affiliation with people in treatment, but also have a sense of deep understanding about their situation. ${ }^{30}$ The involvement of staff with lived experience can be rooted in theoretical concepts such as the social dynamic theory, which stipulates that people will most likely relate to and assimilate information as credible if provided by someone with whom they identify ${ }^{31}$; or the social norms theory, which indicates that people with lived experience are better placed to help people modifying their misperceptions about social behaviours and perceptions. ${ }^{32}$

\section{A good relationship with primary care professionals is key to the recovery journey}

Having a good connection with professionals is key to any healthcare encounter, and interventions targeting drug use are not an exception, as our study shows. Nonspecific treatment factors, such as the therapeutic relationship, are believed to explain between $30 \%$ and $70 \%$ of therapy outcome variance. ${ }^{33}$ Research has shown that a good therapeutic relationship is likely to improve psychological well-being and general distress, ${ }^{34}$ treatment retention $^{35}$ and confidence that the treatment will produce improvements. ${ }^{36}$ Specifically, it has been suggested that a weak therapeutic relationship in drug treatment may contribute to early treatment dropout and a higher level of distress during treatment. ${ }^{3738}$

The importance of the therapeutic relationship is acknowledged in the guidance produced by the Royal College of General Practitioners for the Management of Substance Use. ${ }^{39}$ Considered by RCGP as a 'powerful tool', the therapeutic relationship is however 'inconsistent, unmeasurable and poorly defined' (p. 308). Consequently, further research is needed to explore the main components of successful therapeutic relationships in OST and how we can best support professionals and 
people who use drugs to establish these in clinical practice. From a clinical practice point of view, our study suggests that interpersonal and empathetic attitudes, such as showing kindness, being willing to listen or demonstrating support, should not be underestimated and can boost the attitudes of people who use drugs towards treatment. ${ }^{40}$

\section{A more humanised and destigmatised environment contributes to better treatment experience}

The literature suggests that non-judgemental attitudes are fundamental to engage people with complex biopsychosocial issues. ${ }^{41}$ According to social psychology theories, degrading and discriminatory behaviours within clinical settings, and towards stigmatised groups, are related to unconscious attributions of a lower human status to people, designated as dehumanisation. ${ }^{42}$ In medical contexts, dehumanisation is related to staff avoidance responses, hindering helping behaviours and dementalisation, in which the ingroup (ie, professionals) tends to deny the outgroup (ie, people seeking treatment) the capacity of feeling emotions and goal-planning. ${ }^{42}$ People who feel dehumanised are likely to experience cognitive deconstructive states, sadness and anger, ${ }^{43}$ which can negatively affect their experience in treatment, which is illustrated in our study findings.

The discourse of study participants also pointed to the negative consequences of stigma and self-stigma (I'm a druggie, don't get me wrong) in the recovery journey. This is well documented in the literature, which associates stigma with social identity threat (ie, devaluation based on group membership), higher stress levels and an increased vigilance for signs of mistreatment, leading to situations being interpreted as discriminatory even when they are not. ${ }^{44}$ Experiences of stigma may hinder help-seeking and have a negative impact on other components of recovery, such as employment or reintegration; and reinforce negative feelings of self-worth, self-esteem and blame. ${ }^{45}$

The literature suggests that stigma undermines confidence and self-efficacy, which can be counterproductive to treatment. ${ }^{46}$ As highlighted earlier, being hypervigilant due to experienced stigma may interfere with the development of a trustful relationship with professionals, which is likely to negatively affect treatment. ${ }^{47}$ Further qualitative research is needed to shed light on the processes of stigma and self-stigma in people who use drugs and the role of primary care services in dealing with such experiences of stigma.

\section{Recovery journeys in OST should be flexible, tailor-made and collaboratively designed with people}

Overlooking the uniqueness of a person is another form of dehumanisation in healthcare, as well as denying his/ her personal agency and self-efficacy. ${ }^{42}{ }^{44}$ Our study aligns with these ideas, illustrating how people who use drugs appreciate taking part in clinical decision-making and expressing their thoughts about their recovery journey. A recent review pointed to evidence showing that matching treatment to people preferences contributes to a reduction in drug use. ${ }^{48}$ This aligns with the 'expert patient' approach suggested by Tattersall, ${ }^{49}$ which states that people can 'contribute their skills and insights for the further improvement of services' (p. 227), and that this involvement could help reduce the severity of symptoms and improve confidence, resourcefulness and self-efficacy, which tends to be low in this population. When people feel part of the team, they are also likely to 'care' for the professional in return, which is illustrated by worries such as 'putting too much on the professional. Even though it is debatable whether it is the person's responsibility to care for professionals' well-being, this suggests that a successful therapeutic bond is likely to promote a good and mutually beneficial patient-professional collaboration.

Finally, flexibility was another issue discussed by study participants. Further evidence is needed to explore the impact for staff of being 'immediately available' for people who use drugs, in terms of workload and keeping up professional boundaries. The literature has reported that professionals delivering treatment for drug use are at high risk of burn-out, impacting on their well-being and relationships with people. ${ }^{50}$ However, in this population, there could be consequences to people of limited staff availability and flexibility, particularly when it comes to issues around medication prescription ('I could have relapsed'). For this reason, it is important that training organised locally is provided to professionals who are likely to engage with this group. This would ensure that professionals have knowledge and experience on how to overcome potential challenges of providing OST, as well as the level of support needed by people who use drugs within the remit of each GP practice and the implications of that.

\section{Limitations of the study}

This study is not without limitations. The first of them is the sample size which, even though appropriate for a qualitative study, hinders the generalisability of the findings. A more diverse sample could have been collected, given that there are geographical variations in terms of services provided and availability of staff. For instance, we included GP practices from different locations, but all participating research sites were located in urban contexts, which means that the experiences of participants may not be representative of service users from for example, non-urban GP practices.

Another limitation is that our sample was recruited conveniently through our research team networks and participants were invited through their GPs, due to the research team being unable to identify eligible participants and reach out without their consent. This recruitment strategy facilitated the process of accessing participants, but we are aware of potential GP biases when inviting their patients to the study.

Finally, our recruitment process and how we obtained our sample may have limited our access to patients with negative experiences of treatment and those who are 
less like to adhere to treatment. In the future, it would be important to extend recruitment to harm reduction services, such as supervised injection facilities, to maximise the likelihood of engaging with individuals who may have fewer positive experiences and limited motivation to engage with treatment.

\section{CONCLUSION}

As we face a rise in mortality associated with drug use, and poor treatment retention rates, understanding what people who use drugs appreciate in treatment is paramount. This is particularly important in the context of primary care services, which can be the first point of contact with the healthcare system for many of people seeking treatment.

This study aimed to provide first-hand accounts of how it feels for people to be in OST in primary care services. Overall, our findings point to primary care being a setting that helps people with opioid addiction in their recovery journey. People's accounts have pointed to what works and does not work from their perspective. This knowledge may support primary care professionals managing drug use by raising awareness of how people experience treatment. This study has also suggested that non-specific therapeutic factors, such as empathy, kindness, showing support, willingness to listen or even convenience of location can be powerful tools to facilitate treatment engagement within this group.

In summary, further engagement with people who use drugs will help providers developing an inclusive approach to primary care in the delivery of drug services. This will allow people from stigmatised populations and with complex health needs to receive the highest standards of care, in line with the Word Health Organisation's Alma Ata declaration goal of 'health for all'.

\section{Author affiliations}

${ }^{1}$ Institute for Lifecourse Development, University of Greenwich, London, UK ${ }^{2}$ Primary Care and Population Health, University College London, London, UK ${ }^{3}$ Higher Institute of Social Work of Porto, Senhora da Hora, Portugal ${ }^{4}$ Lusiada Research Center on Social Work and Social Intervention, Lusiada University of Lisbon, Lisboa, Portugal

${ }^{5}$ Epidemiology and Public Health, University College London, London, UK ${ }^{6}$ International Doctors for Healthier Drug Policies, London, UK

Acknowledgements The authors would like to acknowledge the support of the network SMMGP in the study advertisement, as well as the support of $\mathrm{Dr}$ Stephen Willott, Dr Adam Bakker, Dr Jo Newell and Lisa Bowen for their help with recruitment. We would like to thank the service users who supported the various stages of this project, from the study proposal, recruitment and data analysis. We would also like to thank the people with lived experience of drug use who advised on the study methodology and data analysis.

Contributors All authors of this manuscript contributed significantly to the work presented, as follows: conception and design of the work by PCGA, FAS, SM, NP AW and CF; acquisition, analysis and interpretation of data by PCGA, SM and NP; drafting the manuscript and revising it critically for important intellectual content by PCGA, FAS, SM, NP AW and CF; final approval of the version to be published by PCGA, FAS, SM, NP AW and CF; and agreement to be accountable for all aspects of the work in ensuring that questions related to the accuracy or integrity of any part of the work are appropriately investigated and resolved by PCGA, FAS, SM, NP AW and CF.
Funding This work was supported by the National Institute for Health Research School of Primary Care Research, Project No 406 (Reference: SPCR-2014-10043), co-led by PCGA and FAS.

Competing interests None declared.

Patient consent for publication Not required.

Ethics approval Ethics approval was granted from the NHS Health Research Authority/Hampstead Research Ethics Committee (18/L0/1402).

Provenance and peer review Not commissioned; externally peer reviewed.

Data availability statement No data are available. The experiences of people discussed during the interviews refer to sensitive and personally relevant stories, and it was agreed that any transcripts would be made available to the research team only, and not publicly shared to ensure full protection and anonymity of study participants.

Supplemental material This content has been supplied by the author(s). It has not been vetted by BMJ Publishing Group Limited (BMJ) and may not have been peer-reviewed. Any opinions or recommendations discussed are solely those of the author(s) and are not endorsed by BMJ. BMJ disclaims all liability and responsibility arising from any reliance placed on the content. Where the content includes any translated material, BMJ does not warrant the accuracy and reliability of the translations (including but not limited to local regulations, clinical guidelines, terminology, drug names and drug dosages), and is not responsible for any error and/or omissions arising from translation and adaptation or otherwise.

Open access This is an open access article distributed in accordance with the Creative Commons Attribution Non Commercial (CC BY-NC 4.0) license, which permits others to distribute, remix, adapt, build upon this work non-commercially, and license their derivative works on different terms, provided the original work is properly cited, appropriate credit is given, any changes made indicated, and the use is non-commercial. See: http://creativecommons.org/licenses/by-nc/4.0/.

ORCID iD

Paula Cristina Gomes Alves http://orcid.org/0000-0002-1406-5724

\section{REFERENCES}

1 United Kingdom. Country drug report 2019. European Monitoring Centre for Drugs and Drug Addiction, 2019.

2 Office for National Statistics. Deaths related to drug poisoning in England and Wales: 2018 registrations, 2019.

3 National Health Service. Drug addiction: getting help, 2020.

4 Public Health England. Substance misuse treatment for adults: statistics 2018 to 2019, 2019.

5 Madden A, Lea T, Bath N, et al. Satisfaction guaranteed? what clients on methadone and buprenorphine think about their treatment. Drug Alcohol Rev 2008;27:671-8.

6 Ball SA, Carroll KM, Canning-Ball M, et al. Reasons for dropout from drug abuse treatment: symptoms, personality, and motivation. Addict Behav 2006;31:320-30.

7 Rance J, Treloar C. "We are people too": consumer participation and the potential transformation of therapeutic relations within drug treatment. Int J Drug Policy 2015;26:30-6.

8 National Drug Treatment Monitoring System. Alcohol and drug misuse and treatment statistics, 2020.

9 Advisory Council on the Misuse of Drugs. ACMD recovery Committee: second report, 2013.

10 Lawson E. Management of opioid addiction in primary care: a pragmatic approach prioritising wellbeing not ideology. $\mathrm{Br} J \mathrm{Gen}$ Pract 2013;63:231-2.

11 Weaver MF, Jarvis MA, Schnoll SH. Role of the primary care physician in problems of substance abuse. Arch Intern Med 1999;159:913-24.

12 Press KR, Zornberg GZ, Geller G, et al. What patients with addiction disorders need from their primary care physicians: a qualitative study. Subst Abus 2016;37:349-55.

13 Butterfield L, Borgen W, Maglio A. Using the enhanced critical incident technique in counselling psychology research. Can J Couns 2009;43:265-82.

14 Flanagan J. The critical incident technique. Psychol Bull 1954:51327-58.

15 Braun V, Clarke V. Using thematic analysis in psychology. Qual Res Psychol 2006;3:77-101.

16 Nowell L, Norris J, White D. Thematic analysis: Striving to meet the Trustworthiness criteria. Int J Qual Methods 2017.

17 Ford C. The quiet revolution. Druglink 2011;23:1-2. 
18 Schulte MT, Hser Y-I. Substance use and associated health conditions throughout the lifespan. Public Health Rev 2014;35.

19 Murphy S, Irwin J. "Living with the dirty secret": problems of disclosure for methadone maintenance clients. J Psychoactive Drugs 1992;24:257-64.

20 McNeely J, Kumar PC, Rieckmann T, et al. Barriers and facilitators affecting the implementation of substance use screening in primary care clinics: a qualitative study of patients, providers, and staff. Addict Sci Clin Pract 2018;13:8

21 Shin DW, Cho J, Yang HK, et al. Impact of continuity of care on mortality and health care costs: a nationwide cohort study in Korea. Ann Fam Med 2014;12:534-41.

22 Cabana MD, Jee SH. Does continuity of care improve patient outcomes? J Fam Pract 2004;53:974-80.

23 Vimalananda VG, Dvorin K, Fincke BG, et al. Patient, primary care provider, and specialist perspectives on specialty care coordination in an integrated health care system. J Ambul Care Manage 2018;41:15-24.

24 Rapp RC, Xu J, Carr CA, et al. Treatment barriers identified by substance abusers assessed at a centralized intake unit. J Subst Abuse Treat 2006;30:227-35.

25 Reeves D, Pye S, Ashcroft DM, et al. The challenge of ageing populations and patient frailty: can primary care adapt? BMJ 2018;362:k3349.

26 Bouyanni G, Stevens L, Harris M. Gp attitudes to managing drug- and alcohol-dependent patients: a reluctant role. Drug Alcohol Rev 2000.

27 Strang J, McCambridge J, Platts S, et al. Engaging the reluctant GP in care of the opiate misuser: pilot study of change-orientated reflective listening (CORL). Fam Pract 2004;21:150-4.

28 Foy R, Leaman B, McCrorie C, et al. Prescribed opioids in primary care: cross-sectional and longitudinal analyses of influence of patient and practice characteristics. BMJ Open 2016;6:e010276.

29 Georgie J M, Sean H, Deborah M C, et al. Peer-led interventions to prevent tobacco, alcohol and/or drug use among young people aged 11-21 years: a systematic review and meta-analysis. Addiction 2016;111:391-407.

30 National Survey on Drug Use and Health. Center for behavioral health statistics and quality, 2016.

31 Brown JF. Towards a theory of social dynamics. J Soc Psychol 1935;6:182-213.

32 Dempsey RC, McAlaney J, Bewick BM. A critical appraisal of the social norms approach as an interventional strategy for healthrelated behavior and attitude change. Front Psychol 2018;9:2180.

33 de Felice G, Giuliani A, Halfon S. The misleading Dodo bird verdict. how much of the outcome variance is explained by common and specific factors? New Ideas Psychol 2019;54:50-5.

34 Marsh A, Towers T, O'Toole S. Trauma-informed treatment guide for working with women with alcohol and other drug issues. Perth, WA:
Improving Services for Women with Drug and Alcohol and Mental Health Issues and their Children, 2012.

35 Cronin E, Brand BL, Mattanah JF. The impact of the therapeutic alliance on treatment outcome in patients with dissociative disorders. Eur J Psychotraumatol 2014;5. doi:10.3402/ejpt.v5.22676. [Epub ahead of print: 0603 2014].

36 Kim S, Roth WT, Wollburg E. Effects of therapeutic relationship, expectancy, and credibility in breathing therapies for anxiety. Bull Menninger Clin 2015;79:116-30.

37 Meier PS, Donmall MC, McElduff P, et al. The role of the early therapeutic alliance in predicting drug treatment dropout. Drug Alcohol Depend 2006;83:57-64.

38 Urbanoski KA, Kelly JF, Hoeppner BB, et al. The role of therapeutic alliance in substance use disorder treatment for young adults. $J$ Subst Abuse Treat 2012;43:344-51.

39 Drug misuse and dependence. Uk guidelines on clinical management, department of health, 2017.

40 Rowland L, Curry OS. A range of kindness activities boost Happiness. J Soc Psychol 2019;159:340-3.

41 Lee $\mathrm{H}$, Petersen S. Demarginalizing the marginalized in substance abuse treatment: stories of homeless, active substance users in an urban harm reduction based drop-in center. Addict Res Theory 2009;17:622-36.

42 Capozza D, Falvo R, Boin J. Dehumanization in medical contexts: an expanding research field. TPM 2016;23:545-59.

43 Bastian B, Haslam N. Experiencing Dehumanization: cognitive and emotional effects of everyday Dehumanization. Basic Appl Soc Psych 2011;33:295-303.

44 Major B, Mendes WB, Dovidio JF. Intergroup relations and health disparities: a social psychological perspective. Health Psychol 2013;32:514-24.

45 UK Drug Policy Commission. Getting serious about stigma: the problem with stigmatising drug users, 2010.

46 Corrigan PW, Watson AC. Understanding the impact of stigma on people with mental illness. World Psychiatry 2002;1:16-20.

47 Topor A, Skogens L, von Greiff N. Building trust and recovery capital: the professionals' helpful practice. Adv Dual Diagn 2018;11:76-87

48 Friedrichs A, Spies M, Härter M, et al. Patient preferences and shared decision making in the treatment of substance use disorders: a systematic review of the literature. PLoS One 2016;11:e0145817.

49 Tattersall RL. The expert patient: a new approach to chronic disease management for the twenty-first century. Clin Med 2002;2:227-9.

50 Oser CB, Biebel EP, Pullen E, et al. Causes, consequences, and prevention of burnout among substance abuse treatment counselors: a rural versus urban comparison. J Psychoactive Drugs 2013:45:17-27. 